\title{
Originals
}

\section{The Prevalence of Diabetes Mellitus and Impaired Glucose Tolerance in Melanesians and Part-Polynesians in Rural New Caledonia and Ouvea (Loyalty Islands)}

\author{
P.Zimmet ${ }^{1}$, D.Canteloube ${ }^{2}$, B. Genelle ${ }^{2}$, G. LeGonidec ${ }^{3}$, P.Couzigou ${ }^{2}$, M.Peghini ${ }^{2}$, \\ M.Charpin ${ }^{2}$, P. Bennett ${ }^{6}$, T. Kuberski ${ }^{4}$, N. Kleiber ${ }^{5}$, and R. Taylor ${ }^{1}$ \\ ${ }^{1}$ WHO Collaborating Centre for the Epidemiology of Diabetes Mellitus, Royal Southern Memorial Hospital, Melbourne, Australia; \\ ${ }^{2}$ Service de Sante, ${ }^{3}$ Institut Pasteur, ${ }^{4}$ South Pacific Commission Noumea Cedex, ${ }^{5}$ Noumea, New Caledonia; and \\ ${ }^{6}$ Epidemiology and Field Studies Branch National Institute of Arthritis, Diabetes, Digestive and Kidney Diseases, Phoenix, Arizona, USA
}

\begin{abstract}
Summary. The study of different ethnic groups living in the same physical environment provides the opportunity to examine interaction of genetic and environmental factors in the aetiology of diabetes mellitus. In rural New Caledonia, the prevalence of diabetes was higher in part-Polynesians than in Melanesians: males -6.6 versus $0.5 \%$; females -6.3 versus $3.5 \%$ respectively. The prevalence of abnormal glucose tolerance (impaired glucose tolerance and diabetes) was 11.5 and $15.7 \%$ in part-Polynesian males and females, respectively, and 4.7 and $9.2 \%$ in Melanesian males and females. Mean age and degree of obesity in these ethnic groups were sufficiently similar to suggest that these factors played no significant role in the difference in diabetes prevalence. Furthermore, adjust-
\end{abstract}

ment of relative risk of impaired glucose tolerance and diabetes for age and obesity indicated that the modest differences between groups were not responsible for the observed variation in diabetes prevalence. The differences in prevalence of impaired glucose tolerance and diabetes between Melanesians and part-Polynesians may be genetically determined, although the role of certain environmental factors other than obesity, e.g. differences in physical activity or qualitative aspects of diet, cannot be excluded.

Key words: Impaired glucose tolerance, diabetes mellitus, prevalence, Melanesian, Polynesian, glucose tolerance, genetics, environment, rural, urban.
Considerable variation in the prevalence of diabetes has been documented in Pacific populations [1,2]. This has been attributed to an interaction of genetic and environmental factors [1]. Polynesians and Micronesians undergoing modernization of lifestyle have a high prevalence of diabetes [2-8], whereas in their traditional state rates are low [2, 3, 8-10]. Earlier studies in Melanesians showed low diabetes prevalence even in urban environments [11, 12]. However, recent studies in Fiji [13] and Papua New Guinea [14] suggest the situation may be changing.

On the island of Ouvea in the Loyalty Group (part of New Caledonia), Melanesians live side by side with a group of mixed Melanesian-Polynesians (part-Polynesians). Since the physical, social, and economic environment is very similar for both groups, we studied these two ethnic groups in Ouvea to assess whether a difference in diabetes prevalence existed. The study included a rural Melanesian population (from Touho) on the main island of New Caledonia for further comparison.

\section{Subjects and Methods}

\section{Background Information and Sampling Data}

New Caledonia is a French-administered Pacific island territory and is part of the geoethnic area of Melanesia. Populations in the two geographical areas mentioned above were surveyed for diabetes.

\section{Ouvea}

Ouvea is the northern-most of the Loyalty Islands, which lie approximately $100 \mathrm{~km}$ from New Caledonia. It has been maintained as a Melanesian reserve by the French authorities, and is closed to settlers from other areas. The majority of inhabitants are engaged in subsistence agriculture and fishing; copra is the only cash crop.

Ouvea was originally populated by Melanesians from New Caledonia. The majority of part-Polynesians 
trace their origin to Wallis Island (called Uvea), and most to a single legendary migration about $1800 \mathrm{AD}[17$, 18]. These two groups differ in language, geographical location, and religion. The division of the two groups into Catholics and Protestants appears to be an important factor preventing further homogenization of the population. For this survey, an ethnic group was designated for each individual depending on the village of residence.

The Melanesian villagers depend principally on traditional agriculture, producing yams, taro, manioc, sweet potatoes, and some fruits in season. Many of the men fish daily in the lagoon or ocean, and little tinned fish or meat was mentioned in the present survey.

Residents of part-Polynesian villages eat more sugar, white rice, tinned fish, and meat. These villagers are less involved in agriculture and appear to get less from the lagoon than Melanesian villagers. As the more recent arrivals, the part-Polynesians hold and work poorer-quality land than the Melanesians.

Villagers from both groups eat bread with butter when available and drink coffee or tea with sugar. Alcohol is consumed only on festive occasions. The tendency to continue traditional ways is more obvious in the Melanesians. The part-Polynesians consume more refined imported foods.

The last census in New Caledonia was in 1976, and our survey was performed in 1979. It was not possible to conduct another census or to conduct an intensive publicity campaign. A few days before the commencement of the survey in Ouvea, the chief of each village was visited and the nature and purpose of the survey explained. The chief informed his villagers, and they then attended on a voluntary basis. We could not obtain information about those who did not respond.

The population of Ouvea at the 1976 census was 2777 , of whom 2712 were classified as indigenous and, of these, 2284 were born in Ouvea [19]. Of the 623 male inhabitants of Ouvea aged 20 years and over at the 1976 census, 392 attended the survey (response rate: 62\%), and of the 608 females aged 20 years and over, 540 attended the survey (response rate: $89 \%$ ).

\section{Touho}

Touho is a small town located on the north-east coast of New Caledonia, about $300 \mathrm{~km}$ from the capital city of Noumea. The Touho population is a traditional-living, subsistence-farming Melanesian community.

At the 1976 census, the population of the Touho district was 1667. The villages of Touho (172 inhabitants), Koe (224 inhabitants) and Tuai (96 inhabitants) were studied. The total population of these three villages (492) comprises $30 \%$ of the population of the Touho administrative district. A total of 172 people ( 90 males and 82 females) aged $\geqslant 20$ years from these villages were surveyed. Unfortunately, the age/sex breakdown of these villages was not available from the 1976 census.
Assuming that approximately $50 \%$ of the population of the villages surveyed is aged $\geqslant 20$ years (as in Ouvea), the response rate was approximately $70 \%$. The age and sex structure of the Touho sample was similar to that of the total New Caledonia census [19].

\section{Survey Procedure}

The survey was carried out in May and June, 1979. The whole population aged $\geqslant 20$ years in the areas chosen was invited to attend. The subjects had been on unrestricted diets. The average Pacific island daily diet contains over $150 \mathrm{~g}$ of carbohydrate $[4,6,8]$. All subjects were asked to fast and present themselves to the Survey Centre between $0800-0900 \mathrm{~h}$. A fasting blood sample was taken, and a 75-g oral glucose load (Glucomet, Medos, Australia) was administered. Two hours after the glucose load, a further blood sample was taken. The venous blood samples were drawn into Vacutainer tubes (Vacutainer 4572, Becton Dickinson, Rutherford, NJ, USA), each containing $30 \mathrm{mg}$ sodium fluoride. After centrifugation, plasma glucose concentrations were measured on site with a Yellow Springs Scientific Instruments (23 AM) analyser. This uses a glucose oxidase method [20].

Height, weight, triceps skinfold thickness, and blood pressure were also recorded.

\section{Criteria for Abnormal Glucose Tolerance}

The criteria used for abnormal glucose tolerance were based on fasting plasma glucose and the 2 -h post-load plasma glucose values recently recommended by World Health Organization [21] and the National Diabetes Data Group [22]. Since there was no instance in which fasting plasma glucose was $\geqslant 7.8 \mathrm{mmol} / \mathrm{l}$ but 2 -h plasma glucose was $<11.1 \mathrm{mmol} / 1$, this definition is equivalent to one using the $2 \mathrm{~h}$ plasma glucose value only. In subjects who failed to return for the $2-\mathrm{h}$ plasma sample, a fasting plasma glucose of $\geqslant 7.8 \mathrm{mmol} / \mathrm{l}$ was taken as diagnostic of diabetes. Of the eight persons without a 2 -h plasma glucose value, one was classified as diabetic on this basis. These subjects were excluded from further data analysis, apart from the prevalence rates.

Known diabetic patients on treatment were classified as diabetic irrespective of the plasma glucose concentration. Of the six known patients, three also had a 2 -h plasma glucose of $\geqslant 11.1 \mathrm{mmol} / \mathrm{l}$.

\section{Definition of Obesity}

The degree of adiposity was assessed using the body mass index (weight $(\mathrm{kg}) /$ height $\left.(\mathrm{m})^{2}\right)$. Body mass index has been found to be a satisfactory measure of obesity in Polynesian [23] and Caucasoid populations [24]. Relative weight of $120 \%$ ideal body weight corresponds to a body mass index of 27 in males and 25 in females [25].

\section{Statistical Procedures}

In order to compare various groups while controlling for age, direct standardization was used [26]. For this calculation, the study populations were broken down into six age groups $(20-24,25-34,35-44$, $45-54,55-64$, and 65 years and over). The reference population used was the total Ouvea population at the 1976 census [19]. For comparison of age-standardized proportions, the $\chi^{2}$ statistic was used, calculated according to the method suggested by Armitage [26]. For comparison of means, the Student's t-test for unpaired observations was used. For both statistics, the criterion of significance was $p<0.05$.

Relative risks for diabetes and impaired glucose tolerance (IGT) between part-Polynesians and Melanesians, controlling for age and body mass index, were calculated according to the method described by Mantel and Haenszel [27]. $\mathrm{Chi}^{2}$ was used to test the significance of the difference of the relative risk from unity. For these calculations the populations were stratified into three age groups (20-34, 35-54, and 
Table 1. Age and obesity indices in Ouvea and Touho

\begin{tabular}{|c|c|c|c|}
\hline & $\begin{array}{l}\text { Touho } \\
\text { Melane- } \\
\text { sians }\end{array}$ & $\begin{array}{l}\text { Ouvea } \\
\text { Melane- } \\
\text { sians }\end{array}$ & $\begin{array}{l}\text { Ouvea } \\
\text { part- } \\
\text { Polynesians }\end{array}$ \\
\hline Males & $n=90$ & $n=208$ & $n=164$ \\
\hline Age (years) ${ }^{\mathrm{a}}$ & $43.3 \pm 14.1$ & $43.0 \pm 15.0$ & $41.2 \pm 14.9$ \\
\hline Body mass index ${ }^{a}$ & $24.1 \pm 3.1$ & $24.6 \pm 15.0$ & $24.0 \pm 3.2$ \\
\hline \multicolumn{4}{|c|}{ Prevalence of obesity (\%) } \\
\hline Body mass index $\geqslant 27$ & 14.2 & 24.1 & 22.0 \\
\hline Body mass indes $\geqslant 32$ & 2.2 & 3.9 & 1.2 \\
\hline Females & $n=82$ & $n=307$ & $n=237$ \\
\hline Age (years) ${ }^{\mathrm{a}}$ & $41.1 \pm 14.0$ & $42.5 \pm 15.7$ & $43.6 \pm 17.0$ \\
\hline Body mass index ${ }^{a}$ & $24.5 \pm 4.3$ & $26.4 \pm 5.6^{\mathrm{a}}$ & $26.8 \pm 2.0^{c}$ \\
\hline \multicolumn{4}{|c|}{ Prevalence of obesity (\%) } \\
\hline Body mass index $\geqslant 25$ & 39 & 56.0 & $57.3^{\mathrm{b}}$ \\
\hline Body mass index $\geqslant 30$ & 11.0 & 24.1 & $26.1^{\mathrm{b}}$ \\
\hline
\end{tabular}

a Results expressed as mean $\pm \mathrm{SD}$

${ }^{\mathrm{a}} p<0.05{ }^{\mathrm{b}} p<0.01{ }^{\mathrm{c}} p<0.001$ Ouvea part-Polynesian or Melanesian $>$ Touho Melanesian

$\geqslant 55$ years), and quartiles of body mass index (determined from the sex -specific total survey population). The body mass index quartiles for males were $<22,22-23,24-26, \geqslant 27$; and for females $<23$, $23-25,26-29, \geqslant 30$.

Frequency distributions of 2 -h plasma glucose in the various subgroups were constructed after logarithmic transformation. Log base 2 intervals were used for convenience of display of the data in histogram form.

\section{Results}

The means and standard deviations of age in the three populations studied did not differ significantly from one another. However, the prevalence data for IGT and diabetes were age-standardized to the 1976 census to take into account minor differences in age structure between the groups.

Mean body mass indices were similar in the three survey populations, except that the Touho Melanesian females had a significantly lower value than did Ouvea part-Polynesians $(p<0.001)$ and Ouvea Melanesians $(p<0.05)$ of the same sex. The prevalence of obesity was also greater in female Melanesians and partPolynesians from Ouvea when than in female Touho Melanesians (Table 1).

The crude prevalence of IGT and diabetes in each age/sex group in the Ouvea and Touho populations is set out in Table 2. IGT and diabetes prevalence rose with age and was higher in the part-Polynesians than the Melanesians. The IGT rise with age was not as consistent as that for diabetes and the difference between Melanesians and part-Polynesians was more marked for diabetes than for IGT.

The age-standardized prevalence of diabetes and IGT in the various ethnic, geographical, and sex groups is set out in Table 3 . The most impressive ethnic differ-
Table 2. Crude prevalence rates of impaired glucose tolerance (IGT) and diabetes in Ouvea and Touho populations ages 20 years

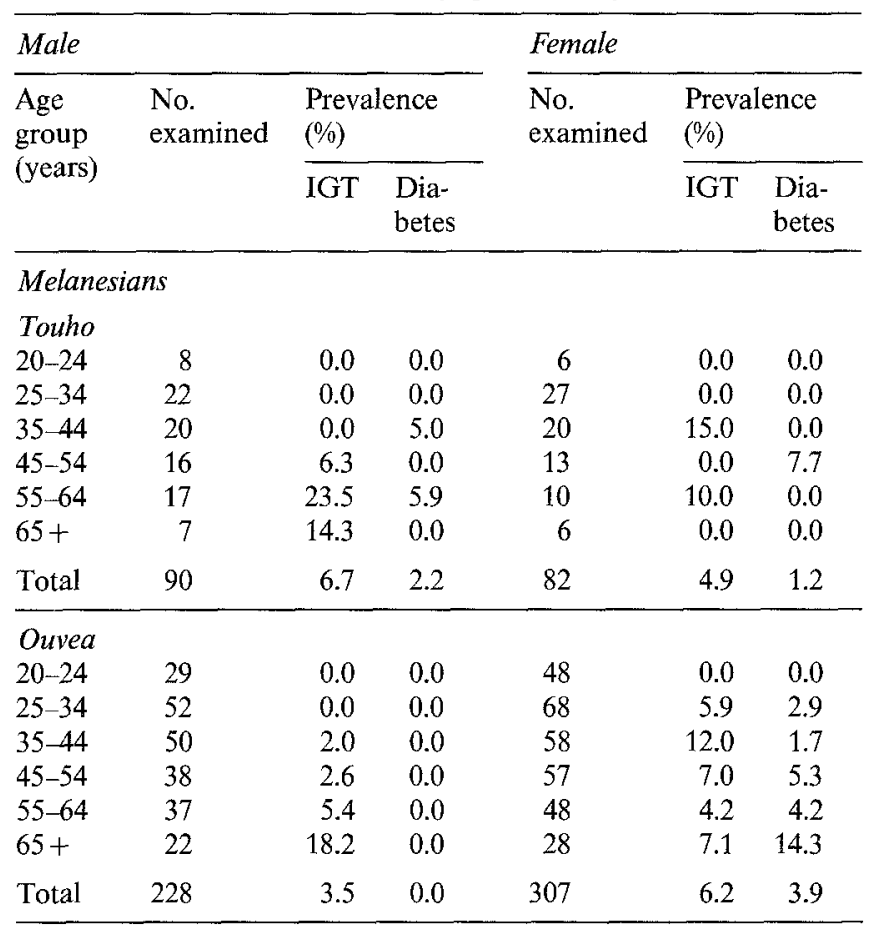

Part-Polynesians

Ouvea

\begin{tabular}{lrrrrrr}
$20-24$ & 25 & 0.0 & 0.0 & 36 & 0.0 & 2.8 \\
$25-34$ & 43 & 2.3 & 0.0 & 55 & 3.6 & 1.8 \\
$35-44$ & 32 & 0.0 & 3.1 & 34 & 11.8 & 2.9 \\
$45-54$ & 34 & 11.8 & 17.6 & 44 & 13.6 & 13.6 \\
$55-64$ & 15 & 6.7 & 20.0 & 30 & 13.3 & 3.3 \\
$65+$ & 15 & 13.3 & 6.7 & 38 & 21.1 & 18.4 \\
Total & 164 & 4.9 & 6.7 & 237 & 10.1 & 7.2 \\
\hline
\end{tabular}

Table 3. Prevalence of impaired glucose tolerance (IGT) and diabetes standardized for age in the various ethnic and sex groups in Ouvea and Touho

\begin{tabular}{|c|c|c|c|}
\hline & \multicolumn{3}{|c|}{ Age-standardized prevalence $(\%)$} \\
\hline & IGT & Diabetes & $\begin{array}{l}\text { IGT }+ \\
\text { diabetes }\end{array}$ \\
\hline Males & & & \\
\hline $\begin{array}{l}\text { Melanesians } \\
\text { Touho } \\
\text { Ouvea } \\
\text { Ouvea and Touho }\end{array}$ & $\begin{array}{l}5.4 \\
3.6 \\
4.2\end{array}$ & $\begin{array}{l}1.6 \\
0.0^{\mathrm{b}} \\
0.5^{\mathrm{b}}\end{array}$ & $\begin{array}{l}7.0 \\
3.6 \\
4.7^{b}\end{array}$ \\
\hline $\begin{array}{l}\text { Part-Polynesians } \\
\text { Ouvea }\end{array}$ & 4.9 & 6.6 & 11.5 \\
\hline Females & & & \\
\hline $\begin{array}{l}\text { Melanesians } \\
\text { Touho } \\
\text { Ouvea } \\
\text { Ouvea and Touho }\end{array}$ & $\begin{array}{l}4.0 \\
6.2 \\
5.7\end{array}$ & $\begin{array}{l}1.3 \\
4.1 \\
3.5\end{array}$ & $\begin{array}{c}5.3^{\mathrm{a}} \\
10.3 \\
9.2^{\mathrm{a}}\end{array}$ \\
\hline $\begin{array}{l}\text { Part-Polynesians } \\
\text { Ouvea }\end{array}$ & 9.4 & 6.3 & 15.7 \\
\hline
\end{tabular}

${ }^{\mathrm{a}} p<0.05 ;{ }^{\mathrm{b}} p<0.001 ;$ Melanesians $<$ Part-Polynesians 
Table 4. Relative risk for impaired glucose tolerance (IGT) and diabetes for Ouvea part-Polynesians compared with Ouvea and Touho Melanesians, controlling for age and body mass index

Relative risk ${ }^{\mathrm{a}}$

Part-Polynesian: Melanesian

$\begin{array}{ll}\text { IGT Diabetes } & \begin{array}{l}\text { IGT }+ \\ \text { diabetes }\end{array}\end{array}$

\begin{tabular}{lccl}
\hline Males & & & \\
Touho Melanesians & 1.5 & 2.9 & 2.0 \\
Ouvea Melanesians & 2.1 & - & $4.5^{\mathrm{d}}$ \\
All Melanesians & 1.9 & $12.5^{\mathrm{d}}$ & $3.4^{\mathrm{d}}$ \\
$\begin{array}{l}\text { Females } \\
\text { Touho Melanesians }\end{array}$ & 1.8 & 5.3 & \\
Ouvea Melanesians & 1.6 & 1.9 & 2.9 \\
All Melanesians & 1.6 & $2.4^{\mathrm{b}}$ & $2.9^{\mathrm{c}}$ \\
\hline
\end{tabular}

a Calculated according to the method of Mantel and Haenszel [27] using three age groups $(20-34,45-44, \geqslant 55$ years $)$ and sex-specific quartiles of body mass index

${ }^{\mathrm{b}} p<0.05,{ }^{\mathrm{c}} p<0.01,{ }^{\mathrm{d}} p<0.001$, for relative risk $>1$

ences are those in prevalence of diabetes between combined Melanesian (Ouvea and Touho) and part-Polynesian males $(0.5 \%$ versus $6.6 \%-p<0.001)$. However, the combined Melanesian females also show a lower prevalence of diabetes than do part-Polynesians of the same sex $(3.5 \%$ versus $6.3 \%$; NS). For each sex, there was no significant difference in IGT prevalence between the ethnic groups. The combined prevalence of abnormal glucose tolerance (IGT and diabetes) was significantly higher in part-Polynesians of both sexes than in Melanesians.

Since Touho Melanesian females were significantly less obese than other female groups, proper comparisons involve standardization for the degree of obesity. The prevalence of diabetes in part-Polynesians was compared with that in Melanesians by calculating relative risk according to the method of Mantel and Haenszel [27], after correcting for age and body mass index, and similarly for IGT (Table 4). The relative risk for diabetes (using corrected data) was significantly greater than unity for part-Polynesians (males 12.5, females 2.4), compared with total Melanesians of each sex. However, relative risks for IGT were not significantly different from unity $(p>0.05)$.

Relative risks for IGT and diabetes (using corrected data) for part-Polynesians, compared with Ouvea Melanesians and total Melanesians, were significantly greater than unity for both males and females.

Frequency distribution of $\log 2$-h plasma glucose concentration for each of the male and female Melanesian and part-Polynesian groups of subjects aged $\geqslant$ 20 years are shown in Figure 1.

In each group, the frequency distribution is unimodal with skewing to the right. Compared with the Melanesian groups, the frequency distribution in the Ouvea part-Polynesians is shifted to the right.

\section{Discussion}

The study reported here is the first epidemiological study of diabetes in New Caledonia. The predominant racial group in these islands is Melanesian, but in Ouvea (Loyalty Islands) an earlier Polynesian migration resulted in some Polynesian admixture. The prevalence rates for diabetes were low in Melanesians of the New Caledonia mainland (males - 1.6\%; females $1.3 \%$ ) and of Ouvea (males - 0\%; females - 4.1\%). The prevalence rates in Ouvea part-Polynesians (males $6.6 \%$; females $-6.3 \%$ ) were higher than in the Melanesian groups, and similar to those reported in other Polynesian populations $[1,2,8]$.

This study indicates that Melanesians have a lower prevalence of IGT (in females only) and diabetes than do part-Polynesians on the same island (Ouvea) and within the same country (New Caledonia). The reason for the differences could be genetic, or a combination of genetic and environmental factors.

Physical, anthropological, and historical evidence suggest that the two ethnic groups studied in Ouvea are likely to be genetically different, at least to some degree. The fact that both groups are living in a similar physical environment suggests that genetic factors may be paramount in causing the Polynesian/Melanesian difference in diabetes prevalence. The similar degree of obesity in most of the groups suggests that differences in weight play a minor role in the observed differences in diabetes prevalence. This is in favour of the genetic hypothesis.

However, it cannot be excluded that environmental factors may contribute. Our anthropological investigation has suggested subtle differences in eating and activity patterns between the two ethnic groups in Ouvea. These are a consequence of cultural, religious, and historical factors. Thus, the Melanesian/Polynesian differences in prevalence of diabetes may be influenced by environmental factors, even though the physical environment of both groups is the same. Furthermore, it is possible for environmental factors to be operating independently of obesity. Certainly, findings in other Pacific populations that we have studied indicate that obesity is not the only factor in explaining variation between genetically identical groups $[8,28]$ in prevalence of diabetes apparently of environmental origin.

Earlier studies in Melanesian countries (New Guinea and Fiji) indicated a low prevalence of diabetes even in urban environments $[11,12]$. These data led to the possibility that diabetes was rare in Melanesians, and that this racial group might have a genetic protection against diabetes - as has been suggested in Eskimos [1].

Two recent studies in Melanesia have called into question the validity of this hypothesis. Martin et al. reported a prevalence of diabetes of $15.8 \%$ in urban residents of Port Moresby in Papua New Guinea [14]. However, the response rate was low for an epidemiological study. We have recently reported a prevalence of $6.9 \%$ 

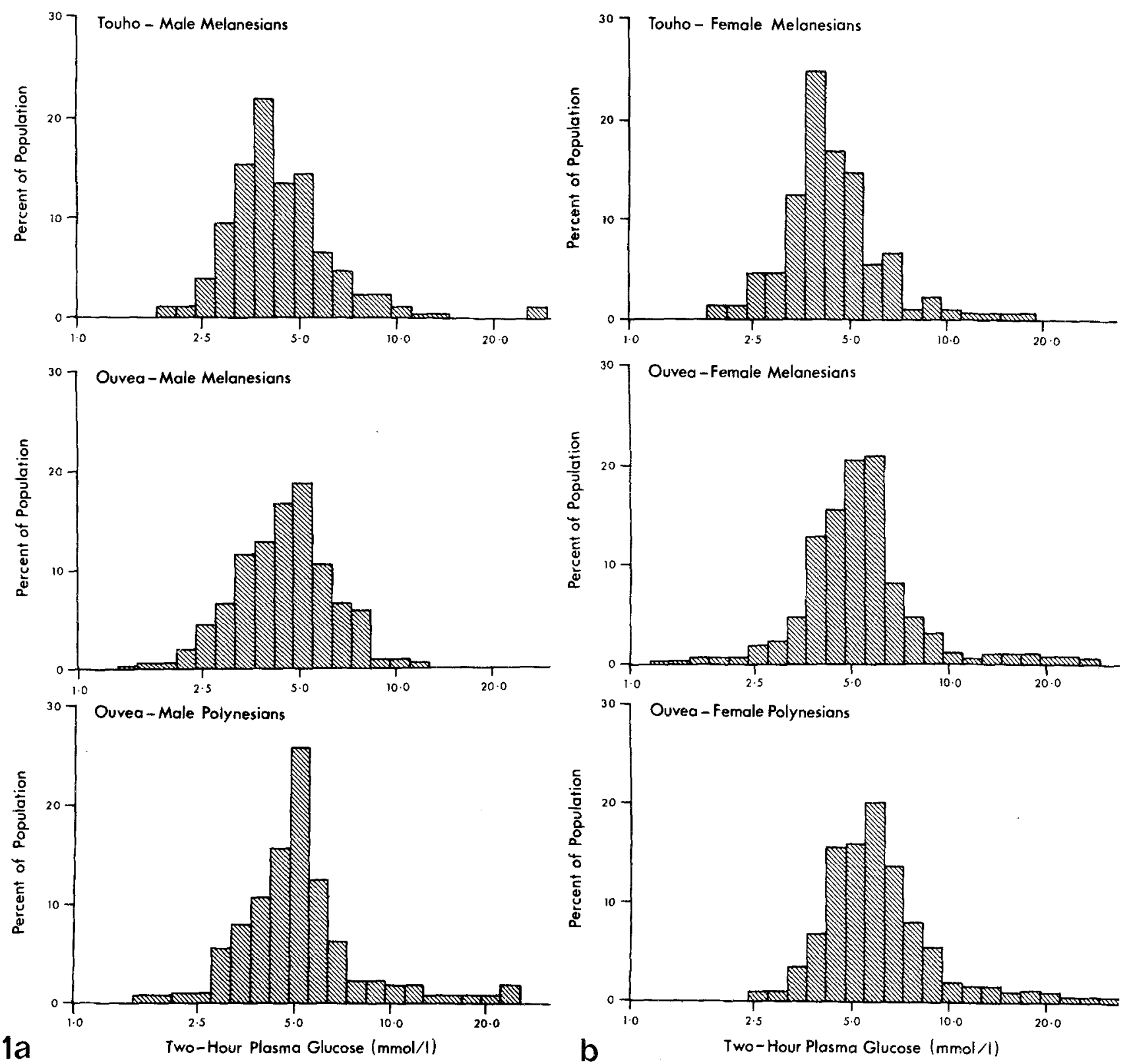

Fig. $1 \mathrm{a}$ and b. Frequency distributions of $2 \mathrm{~h}$-plasma glucose in male and female Melanesians and part-Polynesians

in urban Fijians [13]. These two groups are part of geoethnic Melanesia, but their anthropological origins are closer to Polynesians than are some other Melanesian groups [13].

Both the recent Papua New Guinea and Fiji studies show lower diabetes prevalence rates in rural subjects a phenomenon noted in other Pacific and worldwide studies - whereas the urban prevalence rates are similar to those reported in Polynesian populations. Thus, the question as to whether some Melanesian people do have a true genetic protection against diabetes mellitus remains open.

This study, therefore, gives some credence to the suggestion that at the same (or similar) level of acculturation, some Melanesian groups exhibit a lower dia- betes prevalence than Polynesians, and that this may be genetically determined. However, the possibility that some of the difference may be due to environmental factors other than obesity, for example qualitative aspects of diet (e.g. simple sugar intake, fibre intake) or physical activity, has not been excluded.

Acknowledgements. This study was undertaken as a joint collaborative venture between the Service de Sante, New Caledonia; the South Pacific Commission; and the Royal Southern Memorial Hospital, Melbourne. The study and data analysis were carried out with the generous support of the South Pacific Commission and NIH grant (RO1 AM25446-01). We thank Ms. A. Malpass for preparing the figures, Ms. S. Whitehouse for assistance with the statistical analysis of the data, and Ms. R. Swan for preparation of the manuscript. 


\section{References}

1. Zimmet $P$ (1979) Epidemiology of diabetes and its macrovascular manifestations in Pacific populations: the medical effects of social progress. Diabetes Care 2: 144-153

2. Prior IAM, Davidson F (1966) The epidemiology of diabetes in Polynesians and Europeans in New Zealand and the Pacific. NZ Med J 65:375-383

3. Prior IAM, Rose BS, Harvey HPB, Davidson F (1966) Hyperuricaemia, gout and diabetic abnormality in Polynesian people. Lancet I: 333-338

4. Zimmet P, Seluka A, Collins J, Currie P, Wicking J, DeBoer W (1977) Diabetes mellitus in an urbanized isolated Polynesian population. The Funafuti survey. Diabetes 26: 1101-1108

5. Sloan N (2963) Ethnic distribution of diabetes mellitus in Hawaii. JAMA 183: 419-424

6. Zimmet P, Arblaster M, Thoma K (1978) The effect of westernization on native populations. Studies on a Micronesian community with a high diabetes prevalence. Aust NZ J Med 8: 141-146

7. Zimmet P, Taft P, Guinea A, Guthrie W, Thoma K (1977) The high prevalence of diabetes mellitus on a Central Pacific island. Diabetologia 13: 111-115

8. Zimmet P, Faaiuso S, Ainuu J, Whitehouse S, Milne B, DeBoer W (1981) The prevalence of diabetes in the rural and urban Polynesian population of Western Samoa. Diabetes 30: 45-51

9. Stanhope JM, Prior IAM (1976) The Tokelau Island migrant study: prevalence of various conditions before migration. Int $J$ Epidemiol 5: 159-266

10. Reed D, Labarthe D, Stallones R, Brody J (1973) Epidemiologic studies of serum glucose levels among Micronesians. Diabetes 22: 129-136

11. Price AVG, Tulloch JA (1966) Diabetes mellitus in Papua and New Guinea nea. Med J Aust 2: 645-648

12. Cassidy JT (1967) Diabetes in Fiji. NZ Med J 66: 167-172

13. Zimmet P, Kirk RL, Serjeantson S, Whitehouse S, Taylor R (1982) Diabetes in Pacific populations - genetic and environmental interaction in diabetes mellitus. In: Melish JS, Hanna J, Baba S (eds) Genetic environmental interaction in diabetes mellitus. Excerpta Medica, Amsterdam Oxford Princeton, pp 9-17

14. Martin FIR, Wyatt GB, Griew AR, Haruahelia Mary, Higginbotham Linda (1980) Diabetes mellitus in urban and rural communities in Papua New Guinea. Studies of prevalence and plasma insulin. Diabetologia 18: 369-374

15. Welborn TA, Curnow DH, Wearne JT, Cullen KJ, McCall MG, Stenhouse NS (1966) Diabetes reported by blood-sugar measurement after a glucose load. Report from the Busselton survey. Med J Aust 2: 778-783
16. Howe KR (1977) The Loyalty Islands. A history of culture contacts 1840-1900. Australian National University Press, Canberra, pp 156-158

17. Hollyman KJ (1959) Polynesian influence in New Caledonia. The linguistic aspect. J Polynesian Soc 68: 357-389

18. Guiart Jean (1952) Les Origines de la population d'Ouvea (Loyalty). Stud Melanésiennes 6: 26-35

19. Institut National de la Statistique et des Études Économiques. Resultats du Recensement de la population de la Nouvelle Caledonia. 23 Avril 1976, Paris

20. Brunsman AR (1976) New enzyme probe for glucose analysis. Pittsburgh Conference of Analytical Chemistry, YSI, Yellow Springs, $\mathrm{OH}$

21. WHO Expert Committee on Diabetes Mellitus. Second report (1980) Technical Report Series 646, World Health Organization, Geneva, pp 8-12

22. National Diabetes Data Group (1979) Classification and diagnosis of diabetes mellitus and other categories of glucose intolerance. Diabetes 28: 1039-1057

23. Evans JG, Prior IAM (1969) Indices of obesity derived from height and weight in two Polynesian populations. Br J Prev Soc Med 23: 56-59

24. Keys A, Fidanza F, Karvonen MJ, Kimura N, Taylor H (1972) Indices of relative weight and obesity. $J$ Chron Dis $25: 239-343$

25. Bennett PH (1979) Standardization of methods and reporting of tests in epidemiologic studies. Diabetes Care 2: 98-104

26. Armitage $\mathbf{P}$ (1971) Statistical methods in medial research. Blackwell, Oxford, p 387

27. Mantel N, Haenszel W (1959) Statistical aspects of the analysis of data from retrospective studies of disease. J Nat Cancer Inst 22: 719-748

28. Taylor R, Zimmet P (1981) Obesity and diabetes in Western Samoa. Int J Obesity 5: 367-376

Received: 2 November 1981

and in revised form: 7 May 1982

Associate Professor Paul Zimmet

WHO Collaborating Centre

for the Epidemiology

of Diabetes Mellitus

Royal Southern Memorial Hospital

P O Box 185

Caulfield 3162

Australia 